Article

\title{
Troubadours \& Troublemakers: Stirring the Network in Transmission \& Anti-Transmission
}

\author{
Jeff T. Johnson \\ Independent scholar; Visiting Instructor, Pratt Institute, Humanities \& Media Studies, Brooklyn, NY 11205, USA; \\ raygonne@gmail.com
}

Academic Editors: Burt Kimmelman and Philip Andrew Klobucar

Received: 17 October 2016; Accepted: 4 April 2017; Published: 10 April 2017

\begin{abstract}
With reference to concepts developed in Trouble Songs: A Musicological Poetics, our objective is to locate trouble (and "trouble") in and around song, while attending to media forms, transmission processes, and embodied figures that carry trouble through song. These figures include trouble singer, troubadour and DJ, where the latter combines the roles of media curator, Mixmaster and MC. An exploration of and through these interrelated figures serves to elaborate a theory of transmission and anti-transmission of trouble. In all cases we are concerned with the technology of trouble, as well as modes and techniques for its transmission.
\end{abstract}

Keywords: transmission; anti-transmission; trouble; troubadour; DJ; MC; Mixmaster; Régis Debray; Marvin Gaye

transport [of a message] transforms

—Régis Debray

[I]t is one of the important tasks of poems to short-circuit the transparency that words have for the signified and which is usually considered their advantage for practical uses.

-Rosmarie Waldrop

I am a DJ. I am what I play.

-David Bowie

One

Let's imagine a modern context in which a DJ figure tracks trouble town to town. ${ }^{1}$ She seeks a (power) system (of amplification), just as she plays for and through a system of signs and sounds. We don't have to abandon the idea of a trouble singer ${ }^{2}$ in order to introduce this figure: Our Mixmaster (aka MC) is the trouble singer in another era, with other tools. ${ }^{3}$

1 Originally presented at the Electronic Literature Organization 2014 conference panel "Troubadours of Information: Aesthetic Experiments in Sonification and Sound Technology," with Andrew Klobucar. During the conference panel presentation, the essay was projected behind the speaker, who was accompanied by clips from referenced songs. Each prose block was laid out in landscape view, counterbalanced by associated footnotes. This setup was intended to acknowledge and engage multiple nodes and modes of audience attention, while suggesting a verse-chorus or call-and-response form to the text. Notes were read selectively, and improvised. See Appendix B (Figure A1) for panel framework.

2 See (Johnson 2015; Johnson 2017). The trouble singer is a figure who sings "trouble" in place of "actual" trouble, thus temporarily dispelling the latter and allowing the audience to commune over this exorcism while sharing a sense of their burdens. The Trouble Song summons trouble in an aestheticized form that not only shields the audience (temporarily) from its worries, but protects the singer from a potentially debilitating candor (or public exposure). Meanwhile, the Trouble Song functions as a screen onto which the audience (and the singer) may project their own troubles.

3 We may conflate DJ, Mixmaster and MC, while allowing each term to add layers to our key figure, the trouble singer. (We adopt terminology from the Trouble Songs project, where Trouble Song is a proper noun but trouble singer is not, though 
Furthermore, let's triangulate the $\mathrm{DJ}^{4}$ and the trouble singer with a third figure: the troubadour. We should have reference, recall and recourse to all three (plus) figures while at once imagining them as non-exclusive. ${ }^{5}$ We seek a trouble singer who may be DJ and troubadour, while we recognize the usefulness of making connections and distinctions between these figures.

We listen for (and sing) connections between lyrics and music, while acknowledging that song does not absolutely or necessarily distinguish between the two: Sung (and/or rapped) words become music, $^{6}$ and instruments (be they lyres or synthesizers) speak to us. Over-adherence to formal and technical distinctions brings its own troubles (among them genre trouble, but also a tendency to miss the song while listening to the device), and our objective remains to locate trouble in and around song.

Since we investigate via language, let's look within language for clues, cues and affinities. We begin with "troubadour" and "trouble," in order to imagine the trouble singer as a (modern) troubadour. Along the way, we might re-discover a connection (or a mix, to bring the DJ to the party) between singing and making: The trouble singer has a reputation not only as summoner and evoker of trouble, but as troublemaker and troubler. ${ }^{7}$ Music travels, songs make their rounds, and the troubadour both follows them and leads them from context to context, scene to scene: the troubadour attends. ${ }^{8}$ This may be to confuse the singer for the song, but language and song are full of such confusions, conflations and slippages. ${ }^{9}$ They might even be composed of them. ${ }^{10}$ The songbook of trouble (were there such thing) might itself be a compilation of these confusions.

If Trouble Songs travel in a pre-20th century mode ${ }^{11}$ they are carried place to place by individuals and in migrant cultural practices. The trouble singer performs a social function in bringing "trouble" to town, then taking trouble away. ${ }^{12}$ This economy of trouble follows the lineage of the troubadour, a figure from the High Middle Ages who amplifies love and stirs volatile emotions. The Oxford

the latter usage may appear inconsistent here with the other key figures: DJ, Mixmaster and MC. Let's say the trouble singer is a generic figure that encompasses the other more specific figures.) We think of the DJ (disc jockey) as broadcaster and collector/controller of records_-or media curator. The Mixmaster moniker emphasizes technique (turntablism) and the signal/noise interface signified by the scratch. (We might further explore this path in relation to Kim Cascone's consideration of glitch music as the product of digital tools that enable the foregrounding of error and signal failure, so that audio processing tools, like the turntable, become instruments rather than media. See (Cascone 2004) Meanwhile, the Mixmaster's crossfade (via multiple turntables, along with other devices including laptop and CD console) takes us across media and directs transmission flows between sources. The MC (mic controller) is the rapper or maker of toasts, whose verbal dexterity and feel for the audience serve to monitor and inflect communal affect. We will toggle between these terms to emphasize various roles and skills embodied by our contemporary trouble singer, even while the DJ may combine these roles (as the DJ needs the Mixmaster's technological skills and the MC's genius). Meanwhile, these footnotes will tend to sing a more formal song than the body text, as a more explicit academic backup, or a hybrid (re)mix of Trouble Songs tones, or a straight cover of the same song, a simulcast transmission. Pardon the mixed (troubled?) metaphor. in her multiple guises

As with the media operated by the Mixmaster, they are a confluence of signals.

just as poem becomes song

Here we might add that the troubadour's reputation for knowledge of technique and form evokes the technical (and technological) prowess of the Mixmaster, just as the troubadour's vocality recalls (or preforms) the MC's mic skills.

8 Further along the road, we note the country blues tradition of itinerant musicians after emancipation-as discussed by Leroi Jones in Blues People, and Angela Y. Davis in Blues Legacies and Black Feminism-and the ways these ambulatory cultural practices abet the floating folk lyric, where recognizable phrases hop from song to song and place to place (see also Greil Marcus, "The Old, Weird America" and Luc Sante, "The Invention of the Blues"). This line of thinking is elaborated in Trouble Songs: A Musicological Poetics.

9 Consider the DJ's bag of records, many of which carry the signal of the MC, whose song travels with or without her. Still, the DJ may toast (to sample a term from the origins of hip-hop, at the emergence of the MC's distinct role) over the top of that signal, spinning a new verse over the spinning record(s).

10 Rather than confuse singer for song, we might (remixing Cascone) conflate singer and song with device, and device with the failure of the device. We might then amplify the glitch: synechdochal failure, or device failure as device, or failure for device. The device, too (like or as the song), might carry us (temporarily) away from trouble-or replace one trouble with another. Glitch can be transformative or transporting, but it also signals imminent crash.

11 That is, if we bracket (or delay) for a moment the advent of electromagnetic wave transmission, which will extend and further complicate song travel.

12 Again we go back (and forward) to early 20th century country blues and folk lyric mobility and transfer. This is worth mentioning again because itinerant blues may be considered in the context of this essay as a reference point connecting the troubadour to our contemporary DJ figure-where allusion, floating lyric and sample wax transhistorical. 
English Dictionary traces the etymology of troubadour via the troublesome (and questionable) ${ }^{13}$ verb form "from Latin turbāre to disturb, through the sense 'turn up"" and suggests a comparison with "the form French troubler." Perhaps, then, we can imagine the troubadour as a carrier of trouble: a troublemaker. ${ }^{14}$ Less contested etymology suggests the troubadour finds, invents or composes his song. ${ }^{15}$ That the troubadour is known (and remembered) for love songs puts him on trouble(d) ground, just as the trouble singer seems preoccupied with the vicissitudes of love (as rivaled only by her attention to death-and of course love and death are seldom strangers, not for long and certainly not forever).

The troubadour relates songs of love, and the trouble singer presents a "trouble" lyric to which her audience can relate. ${ }^{16}$ Trouble and love pass through both songs, and both singers. Both figures are trusted and blamed with (and for) carrying their charge. They are artists, servants and provocateurs-and here let us recall that the provocateur is a troublemaker for hire. She stirs trouble, foments sentiment, disturbs and turns up discourse. The troubadour and trouble singer can certainly dig it, as they perform their services, for whatever coin.

The DJ is also a digger (of crates, beats, tropes ${ }^{17}$ ). Whatever she turns up is amplified. Have beats, will travel; have system, will supply power for amplification. Such power calls this version of the trouble singer like a block party DJ to a hackable streetlamp. The moth flies by night and makes a light show of her pursuit. The DJ brings a flock to the light of her mixing board. ${ }^{18}$ Turns it on-pumps up the volume on her amplifier.

Troubadour, trouble singer and DJ are all seekers of the song that finds us where we live: ${ }^{19}$ love, trouble, the beat of our hearts (in and out of our accustomed rhythms). All bring their cargo, their information, their music, from elsewhere, and take something from us as they move along. ${ }^{20}$ We are thankful, skeptical and aroused. In trouble, as in song, we are bereaved, bereft, at a loss, and full of gain. I ain't seen nothing but trouble/... /And I go to the place where good feeling awaits me/ ... /Oh, and I go crazy when I can't find it sings Marvin Gaye in "Flyin' High (In the Friendly Sky)," deep in and far above his own troubles, and ours (Gaye 1972). ${ }^{21}$

13 Indeed, the etymological commentary opens, "The origin of the verb itself is questioned."

14 Whether this figure might also either be a troubleshooter, or might seem to require troubleshooting, remains to be seen.

15 Here the etymological connection between troubadour and the medieval Latin tropus, via trope (again per OED) connects with verse, which suggests a sense-making prosodic arrangement we might also think of as version, mix or flow. This related sense of trope as verse phrase also evokes a (call and) response as introduced in the medieval Western Church and carried through MC flow.

16 The successful Trouble Song lyric balances pathos and detail with a generic sense of inclusiveness and discretion, which protects singer/listener privacy while allowing for communal feeling and commiseration.

17 which she turns, literally, a remix of trope's etymology from Greek tropos, 'turn'

18 making use of the MC's geniality and the Mixmaster's technique, which are no sweat (see here Erik B. \& Rakim's foundational hip-hop album Don't Sweat the Technique).

19 The song finds us by ear and by eye. The DJ sees what she plays, from cover to groove, while the Mixmaster sees sounds as wave forms to be manipulated, amplified, numerically sampled, patterned as information. Meanwhile, at least in retrospect, we all see trouble coming.

20 Allow us to reintroduce the troubadour, who models a form of cultural remix, where historical traditions are de-contextualized, then re-contextualized in the mix for contemporaneous situations and loci. Much is brought to the transhistorical party, including more trouble: a provisional order is established with a wink, set up to be knocked down as the revelry gets underway.

21 As we'll see (and can hear for ourselves), What's Going On (Gaye 1971), from which this cut comes, is full of trouble. A year later, Gaye graces the album cover of the soundtrack to Trouble Man, above a spliced action shot of the lead film actor (the composition shaped in a $\mathrm{T}$ for Trouble with a capital $\mathrm{T}$, while the $\mathrm{O}$ in trouble and the $\mathrm{A}$ in Marvin are shot through with extra holes). He sings its title song and adds vocal textures to a few other numbers, but the album is mostly instrumental and incidental accompaniment to the Blaxploitation film by the same name. This is a whole other world of (representational) trouble, outside the scope of this essay, though in terms of Trouble Songs' musicological poetics, we might say the Trouble Man character Gaye doubles for on the soundtrack plays the part for those who want a taste of trouble without paying for their meal: "Trouble" in place of trouble, as Trouble Songs has it, and as explored above (or below) in a moment. 


\section{Two}

As Robert Casillo has it, "[M]etonymy is defined as the substitution of the container for the contained" (Casillo 1985, p. 142). So "trouble" as a linguistic container promises, in the Trouble Song, to dispel trouble. This is not the way language is supposed to work; rather, it's the way language works. The trouble singer makes slippage work for her.

\section{Three}

"[T]he troubadour poem is supplementary, an attempt to overcome absence, difference, and delay" (Casillo 1985, p. 139). Whereas the trouble singer attempts to amplify the absence, difference and delay of trouble with the application of "trouble," the troubadour seeks to prolong the unconsummated heart-on, presenting poem as fetish for the lady (or object of desire in the troubadour's song). But if, as Casillo goes on to suggest, the troubadour makes his living ${ }^{22}$ by forestalling consummation (his own and others'), he has something in common with the trouble singer, who sings trouble away with "trouble." (Here is the transmission of anti-transmission, where the audience gets exactly what it bargains for.) ${ }^{23}$ For his part, the troubadour sings love (intercourse) away with "love" (the language of desire in song).

\section{Four}

A syllogism, of sorts:

troubadour-song-lady; trouble singer-song-trouble

This is a formal and relational comparison, with song at its fulcrum: all terms are not equivalent. The lady is not trouble, despite what the boys might say. But the object of the troubadour's song confers with the object of the trouble singer's song. The troubadour claims to draw the lady closer, while pushing her (tantalizingly) away, ${ }^{24}$ and the trouble singer calls "trouble" to put trouble at bay. ${ }^{25}$ To stir up, then forestall, remains a powerful linguistic gesture, in any medium, with any toolset. "Trouble"? What trouble?

\section{Five}

Let's add our third figure to the mix:

troubadour-song-lady; trouble singer-song-trouble; DJ-track-beat

The DJ is one who DJs-as Mixmaster, the one who drops (and turns/tropes) the beat. The mode of transmission remains the song (or track[s]). ${ }^{26}$ As ever, the song is mix and remix, informed and composed of cultural material. Like our first two figures, the DJ/Mixmaster stirs up and forestalls: finds the hook, ${ }^{27}$ loops it into her beat, and lets it spin. Here we call to mic the MC, who might ride the beat and let "trouble" flow. We might also consider the breakbeat, for which the Mixmaster finds and loops a drum pattern ${ }^{28}$ to literally forestall a climax in her track. This may be accomplished via turntables and crossfader or with a digital sampler and sequencer.

22 or gets around

23 And let's recall the Mixmaster's crossfader, which re-places or conflates one song/signal for another, and makes possible the potentially infinite dilation of the break (as we'll see).

24 And yuck, etc. This heteronormative and sexist display is ripe, of course, for drag dressing-up-as-dressing-down via torch song.

25 a refrain, to refrain: She has no intention of calling trouble itself, except to call it "trouble" - to re-place trouble (elsewhere, anywhere but here).

26 city to city, beat to beat.

27 Here we find Wikipedia's entry for hook to be of use (recognizing also the suitability of this source, as cultural and linguistic sample and remix): musical idea or short riff.

28 Archetypal breakbeats come from James Brown's "Funky Drummer" or The Incredible Bongo Band's "Apache," as mixed on two turntables by DJ Kool Herc (circa early '70s in The Bronx), as he cut between two copies of the same record to extend the drum break for the benefit of the b-boys and b-girls on the dance floor. 
"The transmission, or the transport of information in time, is to be distinguished radically from that of communication, or the transport of information in space, even if they combine in reality," writes Régis Debray, in "What is Mediology?" (Debray 1999, as translated by Martin Irvine). We might consider the transport of information in time as a description of song, and in the case of the Trouble Song, what follows is true: We may radically distinguish this transport of "trouble" from communication of trouble. As for the transport of information in space, whether or not it is distinguished from communication, the trouble singer complicates or even frustrates such transmission, by design. Consider again the floating lyric - that is, tropes borrowed and re-turned (or re-tuned) by the singer. Troubles, troubles, I've had them all my days; trouble in mind; trouble on the line; leave your troubles behind; nothing but trouble. ${ }^{29}$ These tropes turn up here having come from elsewhere, but we've heard them before and can't be sure they crossed a line from there to here. Or we know the lines are crossed, but can't be sure if these bits of information transmitted here to there or there to here, or if they were and are always here and there, a circuit lit up..$^{30}$ Debray again: "[T] he origin is what arises at the end." Process does not necessarily imply procession from a point of origin. ${ }^{31}$ The song was always here and always there, ${ }^{32}$ but the trouble singer performs the magic of transport in which "trouble" arrives to take (or keep) trouble away, and we too are transported: to and from trouble, via song. And still: Every Trouble Song sings to (and from) the others. Thus "trouble" is transmitted, and trouble is transmuted.

\section{Seven}

"The object of transmission does not preexist the mechanism of its transmission" (Debray once more). We necessarily (and correctly) confuse the figure-: troubadour, trouble singer, DJ—for the message-: love, trouble, beat. Each is associated with a technique and a technology; $; 3$ nor can we any longer distinguish the analog from the digital. The DJ's media were record and turntable, and now include the laptop ${ }^{34}$-all of which require, as does the DJ, a system of amplification, and an audience to receive the transmission (or anti-transmission, in the case of the Trouble Song).

\section{Eight $^{35}$}

Marvin Gaye sings into the intercom, "Flyin' High (In the Friendly Sky)" without ever leaving the ground. From his view, he sees nothing but trouble, and spins this trope, his for the song, a floating lyric transmitted to us, hung over the precipice of good feeling and self-destruction. Gaye's voice, above the strings, vibes and rhythm, carries us where the singer can't go. Nobody really understands, he sings, sparing us. Gaye announces, in the liner notes for the 1971 album What's Going On, "[Y]ou shouldn't have to pay any special attention to the lyric on 'Flyin' High In the Friendly Sky' just because I think you ought to. ${ }^{\prime \prime 6}$ End transmission.

29 see also Appendix A: “Trouble Will Find You” (from Trouble Songs: A Musicological Poetics, in which a version of this essay appears).

30 or, again, two turntables linked by crossfader.

31 Nor does the troubadour arrive (though he attends the song)-always out of place, the troubadour (like the Mixmaster et al.) is stuck in a loop of here/there. Just so, the trouble singer rides the break (sic) of trouble/"trouble."

32 And here we can further illustrate and complicate the matter with reference to electromagnetic radio waves and wireless communication, where source and signal translocate and exist in multiple and proliferant destinations, and the nature, form and format of the source is transmogrified.

33 where (in this verse) technique is delivery, and device (be it metaphor, guitar or computer) is technology.

34 the medium and the tool/instrument.

35 Here we turn 8 on its side, lower it to the turntable, and loop the next track.

36 It's up to you, of course. If you do keep the song spinning, and listen through Gaye's delivery to the words, which are perfectly clear even as they soar above signification, you'll hear a cocaine blues, probably, but you'll also hear a love song, and a song of brotherhood. You'll also hear, in the last, circling verse, the boy who makes slaves out of men to whom the song — and the singer-is hooked. You might also notice the way the previous song, "What's Happening Brother," lands on the opening vocal oohs of "Flyin' High," making the connection between the returning soldier and the troubled mind. Can't find no work, can't find no job my friend sings the soldier in "What's Happening Brother," and the grounded pilot answers 
Conflicts of Interest: The author declares no conflict of interest.

Appendix A. A Sample Index of Trouble Song lyrics, Typically in Order of Appearance in Trouble Songs: A Musicological Poetics

\section{Trouble Will Find You}

1,2

Trouble, trouble, I've had it all my days Trouble with a capital T Trouble with people like me Trouble, trouble, it seems like trouble going to follow me to my grave She was drinking down her troubles Have trouble at my door Troubles, no troubles, on the line They'll wash your troubles, your troubles, your troubles away In that troubled water Trails of troubles When I've got trouble even opening a honey jar I told you I was trouble Trouble in mind, I'm blue Trouble falls in my home Troubled man, troubled stone You wanted trouble We are the trouble

Ain't that asking for trouble Have you ever been in trouble Trouble ahead, trouble behind Everyone around me knows I'm in trouble Because I've got troubles enough He never took much trouble Don't it make your troubles seem small They tell me when you tell somebody your troubles Trouble fly away from you Then when you're just about to doze, fly trouble And there was trouble, taking place I got girl trouble up the ass I thought about trouble trouble Where's my little trouble girl? We would stay out of trouble If you decide to make me blue, I'll be in trouble So I just want you to know, I'll be in trouble You're in love and I'm in trouble Keep smiling at trouble 'cause trouble is a bubble Little trouble girl Well, this trouble in the house Trouble on the stairs Trouble in the trouble That trouble in the air Nobody knows the trouble I've seen We don't need no more trouble Tiny bubbles are always leadin' me knee deep into some sort of trouble Wisdom forgot them so they became trouble So much trouble in the world Think about your troubles We spell trouble Trouble in the city, trouble in the farm Trouble, trouble, trouble Nothin' but trouble Oh trouble set me free I think I'm in trouble Trouble come running Trouble where the kids are You end up here in trouble and strife I won't be trouble no more The trouble boys came in To get my baby back from the trouble boys What's the trouble down here? Knowin' the trouble down here below He was having trouble That's the trouble in this world Oh Lord I'm sorry, but there's trouble on the line Does it become you troublemaker 'Cause trouble man don't get in my way You ain't gonna trouble poor me anymore Well I pulled on trouble's braids But remember troubles don't always last Nobody knows my trouble Bad luck and trouble I'm through with all my trouble Now I'm blue and the trouble with me is you When a woman gets in trouble everybody throws her down There ain't but one thing worth my trouble in mind Wrap your troubles in dreams You've got your troubles and I've got mine

I knew you were trouble when you walked in One kiss and that spells trouble Trouble, trouble, trouble, trouble, trouble Looking for some trouble tonight Never woulda seen the trouble that I'm in Trouble's what feels good to me Papa don't preach, I'm in trouble deep She's trouble, in a word get closer to the fire Trouble seemed so far away I dance to escape my troubles I'm not looking for trouble We in trouble but you won't meet me at the bridge We don't cause trouble, we just ride

In the morning, I'll be alright, my friend, before correcting himself later in "Flyin' High": Well I know I'm hooked, my friend. He knows well the answer to the soldier's final question, What's been shakin' up and down the line (and the soldier knows he knows-just like the album title, his question has no question mark): Without ever leaving the ground/...I ain't seen nothing but trouble baby. 
Appendix B. Notes (via Andrew Klobucar, as Presented at the Electronic Literature Organization 2014 Conference Panel "Troubadours of Information: Aesthetic Experiments in Sonification and Sound Technology")

A. Écouter, is listening to someone, to something; and through the intermediary of sound, aiming to identify the source, the event, the cause, it treats the sound as a sign of this source, this event (Concrete/Objective).

B. Ouïr, to perceive by the ear, to be struck by sounds, it is the crudest level, the most elementary of perception; so we "hear", passively, lots of things which we are not trying to listen to nor understand (Concrete/Subjective).

C. Entendre, here, according to its etymology, means showing an intention to listen [écouter], choosing from what we hear [ouïr] what particularly interests us, thus "determining" what we hear (Abstract/Subjective).

D. Comprendre, means grasping a meaning, values, by treating the sound like a sign, referring to this meaning as a function of a language, a code (semantic hearing; Abstract/Objective).

\begin{tabular}{lll}
\hline & Abstract & Concrete \\
\hline Objective & 4. Comprendre & 1. Écouter \\
Subjective & 3. Entendre & 2. Oü̈r \\
\hline
\end{tabular}

Figure A1. Schaeffer's quatre écoutes, his four modes, or ways, of listening (1967).

\section{References}

Cascone, Kim. 2004. The Aesthetics of Failure: 'Post-Digital' Tendencies in Contemporary Computer Music. In Audio Culture: Readings in Modern Music. Edited by Christoph Cox and Daniel Warner. Continuum: New York, pp. 392-99.

Casillo, Robert. 1985. Troubadour Love and Usury in Ezra Pound's Writings. Texas Studies in Literature and Language 27: $125-53$.

Debray, Régis. 1999. What Is Mediology? Translated by Martin Irvine. Le Monde Diplomatique: 32.

Gaye, Marvin. 1972. Trouble Man. Hollywood: Tamla.

Gaye, Marvin. 1971. What's Going On. New York: Tamla, LP record.

Johnson, Jeff T. 2015. Trouble Songs: A Musicological Poetics. Jacket2, May 18. Available online: http://jacket2. org/article/trouble-songs (accessed on 5 April 2017).

Johnson, Jeff T. 2017. Trouble Songs: A Musicological Poetics. Earth, Milky Way: Punctum Books.

(C) 2017 by the author. Licensee MDPI, Basel, Switzerland. This article is an open access article distributed under the terms and conditions of the Creative Commons Attribution (CC BY) license (http:/ / creativecommons.org/licenses/by /4.0/). 